\title{
SABERES E SABORES DA COLÔNIA CD-ROM INTERATIVO, COM LIVRO DE RECEITAS
}

\section{Cíntia Hoffmeister Rizzi ${ }^{1}$}

O CD-ROM Saberes e Sabores da Colônia, organizado por Renata Menasche ${ }^{2}$, Claudia Turra Magni ${ }^{3}$ e Mauro Bruschi ${ }^{4}$, é um produto multimídia com fotografias, textos, videoclipes e um livro de receitas impresso que está entre os resultados ${ }^{5}$ do projeto Cultura, patrimônio e segurança alimentar entre famílias rurais: etnografias de casos significativos, parte da agenda de pesquisa Saberes e Sabores da Colônia ${ }^{6}$, realizada entre 2011 e 2013 na Serra dos Tapes (Pelotas), sul do Rio Grande do Sul. Teve por objetivo identificar, caracterizar e conhecer, através de práticas alimentares, os diversos grupos camponeses locais e seus modos de vida.

A apresentação do CD-ROM faz alusão a uma mesa que se funde com paisagens locais onde os ícones abertura, localidades, saber fazer, festar e consumir o rural estão dispostos para serem “degustados” pelo navegador.

Clicando em Localidades, uma encruzilhada se apresenta, possibilitando ao navegador escolher o caminho a seguir. Clicar em uma das placas conduz ao destino escolhido: Colônias Maciel e São Manoel; Coxilha dos Campos; Butiá; Santa Augusta e Arredores e Torrão, Picada e Rincão das Almas. Cada destino apresenta um pequeno texto informativo sobre a localidade, enquanto os ícones câmera fotográfica e filmadora dão acesso às fotografias e aos videoclipes ${ }^{7}$ realizados pela equipe durante a pesquisa.

\footnotetext{
${ }^{1}$ Universidade Federal do Rio Grande do Sul, Brasil.

2 Antropóloga, professora do Instituto de Ciências Humanas da Universidade Federal de Pelotas (UFPel). Pesquisadora do Laboratório de Estudos Agrários e Ambientais (LEAA), coordenadora do Grupo de Estudos e Pesquisas em Alimentação e Cultura (GEPAC).

3 Antropóloga, professora da Universidade Federal de Pelotas (UFPel). Coordenadora do Laboratório de Ensino, Pesquisa e Produção em Antropologia da Imagem e do Som (LEPPAIS).

${ }^{4}$ Artista plástico MBA desenhos.

5 Apresentações de trabalhos em congressos científicos, artigos publicados, monografias, dissertações e no livro Saberes e Sabores da Colônia: modos de vida e patrimônio alimentar entre os pomeranos no Brasil Meridional (FAPERGS 1018354/2010), publicado pela editora da UFRGS em 2014.

${ }^{6}$ Realizada pelo Grupo de Estudos e Pesquisa em Alimentação e Cultura (GEPAC/PGDR/UFRGS), em associação com o Laboratório de Estudos Agrários e Ambientais (LEAA/UFPel)) e com o Laboratório de Ensino, Pesquisa e Produção em Antropologia da Imagem e do Som (LEPPAIS/UFPel).

${ }^{7}$ Os videoclipes são fragmentos dos filmes produzidos durante a pesquisa e se encontram disponíveis para visualização completa em http://www.ufrgs.br/pgdr/gepac/videos.html
} 
O viajante pode desbravar terras habitadas por descentes de colonos imigrantes italianos, alemães, pomeranos, franceses, negros e indígenas das etnias Mbyá-Guarani e Tapes. É possível andar por campos de fumo e parreirais, e ainda aprender com os remanescentes de quilombos das localidades Torrão, Picada e Rincão das Almas como fazer "chimia" de melancia de porco. O videoclipe Oficina sobre hábitos alimentares: trocas de saberes, de Maurício Schneider (2013, 17 min.) e as fotografias da Família Camelato durante a colheita da uva são ilustrativas destas paisagens e modos de vida.

Saindo das localidades, o navegador pode aventurar-se pelo Saber Fazer. O ícone apresenta conhecimentos e práticas compartilhados, ligados à produção de alimentos tradicionais, associados às formas de cuidado com a terra e animais, de manejo e cultivo, de técnicas de processamento e de utensílios que estão inseridas no modo de vida das famílias produtoras conformado todo o sistema. Nas laterais do texto estão dispostos os ícones fogão, que apresenta fotos de diversos fogões à lenha, inserindo o explorador nos espaços domésticos das famílias, e panela, que permite acessar diversas receitas locais ${ }^{8}$ feitas com os ingredientes mais utilizados pelas famílias: trigo/ porco/ milho/ uva/ ervas medicinais/ batata/ ganso/ melancia de porco. As imagens de cada um desses ingredientes conduzem a textos, fotografias e videoclipes sobre os alimentos e seus usos.

Em porco destaca-se o videoclipe Carneação de porco, de Patrícia Pinheiro (2013, 12 min.) que apresenta como esse processo acontece no Quilombo Picada, em São Lourenço do Sul, desde "matar o porco sem pena" até o corte da carne e sua importância para essa comunidade. Degustar milho significa experimentar também o passado e as lembranças boas que este alimento traz, das maneiras de como era preparado e das serenatas e festas que hoje já não acontecem mais, como em Memórias negras sobre alimentação, de Patrícia Pinheiro (2013, 14 min.), que trata das memórias dos habitantes do Quilombo Rincão das Almas. Uva nos permite um passeio pelas Colônias Maciel e São Manoel e por sua produção de vinhos e sucos. As fotografias e o videoclipe Família Camelato, do vinho e do suco, de Carmen Machado (2013, 25 min.) retratam o saber fazer, desde o apanhar das uvas até o engarrafamento para comercialização. Mas o material revela que este saber não ficou restrito aos descentes de imigrantes italianos, estando também presente entre descentes de alemães e "brasileiros". Ao clicar em batata, é possível conhecer o Rievelsback, prato de origem

\footnotetext{
${ }^{8}$ Waffal, doss, mocotó, riwalsback, cuca alemã bolachinha de polvilho, bolachinha de milho, schimier de melancia de porco, pão de batata, bolo de milho, bolo de torresmo, canjica doce, quibebe e bolo de pedra.
} 
pomerana que tem como base a batata e pode ser utilizado no preparo de outras receitas. Uma antiga prática culinária entre os pomeranos pode ser apreciada quando clicamos em ganso: Spickbost (peito de ganso defumado). As fotografias e o videoclipe Saberes $e$ Sabores da Colônia: o peito de ganso defumado, de Evander Eloí Krone (2013, 21 min.) registram este saber fazer tradicional pouco conhecido fora da região. O clipe “Preparo da Schimier de Melancia de Porco”, de Maurício Schneider (2013, 12 min.), e as fotografias revelam as diferenças e semelhanças no modo de fazer e nas sociabilidades, entre pomeranos e quilombolas.

A maioria dos grupos camponeses da região faz uso frequente de ervas medicinais em chás, temperos e bebidas. A maischnaps (cachaça de maio), feita pelos pomeranos, é muito utilizada por seus efeitos medicinais, principalmente em problemas de digestão.

Clicando em Festar, o CD-ROM apresenta um pequeno texto relatando como acontecem as festas da colônia, nas quais, como é de costume, há bebida, muita comida e gente reunida em torno da mesa. De uma forma geral, as festas guardam características comuns: são tradicionais e anuais. Organizadas em mutirão, estão integradas ao calendário religioso e agrícola, marcando o ano das famílias camponesas. Ícones com imagens de igrejas, distribuídos acima do texto, evidenciam a forte ligação entre as festas e a religiosidade. Ao clicar na primeira igreja podemos participar da Festa de Sant'Ana, padroeira das Colônia Maciel, São Manoel, Santa Áurea e outras. Festa na Colônia, Festa de Sant'Ana, de Carmen Machado (2013, 35 min.), revela como acontecem esses eventos, desde o início, com a missa, passando pelo churrasco ao ar livre, o café colonial e finalizando com o baile, elementos recorrentes nas outras festas de colônia. Em “Terno de Reis”, de Patrícia Pinheiro (2013, 13 min.), é possível conhecer parte das festividades associadas a uma manifestação tradicional tão importante em meio à riqueza cultural desta região pluriétnica e diversa.

Consumir o local apresenta o texto $O$ rural que a cidade consome e cinco ícones: feiras/ restaurantes/ agroindústrias/ caminho pomerano/ sudoktoberfest, que tratam dos circuitos de produção e consumo entre cidade e campo, revelando uma tendência crescente nos centros urbanos: a de se buscar, nas feiras ecológicas, produtos associados positivamente à natureza e à tradição, às identidades étnicas e sabores típicos da colônia, às suas rotas, caminhos e localidades. 
Restaurantes é um ícone particularmente interessante, pois leva a um passeio ao Café Cultural servido na Jeske's - casa de café e cultura pomerana, que oferece pratos de herança familiar. $\mathrm{O}$ espaço abriga um pequeno museu com antigas peças de famílias de imigrantes pomeranos instalados na Serra dos Tapes. Caminho Pomerano aborda uma rota turística que visa valorizar o patrimônio cultural pomerano, sua zona rural, seus costumes, pratos e bebidas. Sudoktoberfest abre com um texto abordando a necessidade que alguns jovens, integrantes do grupo de danças folclóricas alemãs Sonnenschein, tinham de criar uma espécie de Oktoberfest no sul do Rio Grande do Sul. A Sudoktoberfest envolve um jantar típico, apresentações de corais e grupos de dança, escolha e desfile das soberanas da festa, bailes, e jogos germânicos tais como o jogo de cartas conhecido localmente como Schafskopf.

Realizar este passeio-leitura-viagem cultural agradável, prazeroso e singular foi um privilégio proporcionado por este CD-ROM. Primeiro pela importância deste trabalho, que registra patrimônios alimentares e culturais dos habitantes dos diversos lugares da região, abrigando identidades, raízes, memórias, expressões culturais e suas resistências. Junto a isto, cores, texturas, aromas, sabores e saberes que envolvem, no ato de comer e de preparar as receitas, sociabilidades e rituais característicos daquelas pessoas e daqueles lugares.

É um material didático e pedagógico que pode ser utilizado em escolas locais como forma de explorar e conhecer aspectos culturais de sua realidade e em escolas de outras regiões com o intuito de divulgar e discutir a diversidade cultural. As belas imagens dos pratos típicos de cada localidade instigam o navegador a visitar a região, ao mesmo tempo em que excitam os sentidos. O aspecto estético do material merece destaque: a cada clique, uma bela imagem estilizada de alimentos ou paisagens se apresenta ao fundo da tela, enchendo os olhos de quem as vê. A curiosidade para o restante dos trabalhos da pesquisa se aguça, levando o leitor-navegador a buscar as outras produções disponíveis em sites, livros e relatórios.

Outro aspecto importante a se considerar é que o CD-ROM é um excelente modo de produção e difusão de conhecimento, que agrega imagens, textos informativos e suas conexões. Permite praticar a liberdade e a criatividade, porque rompe com a linearidade dos textos escritos, modificando o ritual de leitura. O caminho é trilhado pelo leitor-navegador. 
Este rico material permite refletir sobre como, na antropologia, pode-se utilizar de diversas formas narrativas (imagem, texto e som) para pensar sobre modos de vida, modos de fazer e tradições, evidenciando como as práticas alimentares e as cozinhas regionais, com seus sabores específicos, podem trazer à tona questões de grande relevância para a análise social, tais quais etnicidades, resistência cultural, conflitos, sociabilidades, relações de gênero e outros temas.

Recebido em: 28/09/2015. Aprovado em: 06/04/2016. 